\title{
Social cognition and communication skills in Asperger syndro- me young adults
}

\author{
Mónica Figueira, Inmaculada Fuentes-Durá* y Juan Carlos Ruiz \\ Faculty of Psychology, University of Valencia, Spain
}

(Received October 2, 2013; Accepted October 28, 2013)

\begin{abstract}
The aim of this study is to compare patients with Asperger syndrome (AS) and control participants on social cognition tasks and communication skills. Twenty young adults were assessed in three social cognition domains; recognition of basic emotions, recognition of complex emotions and Theory of Mind (ToM). In addition participants completed a self-report questionnaire as a measure of social communication skills. The results indicate that adults with AS perform below neurotypical control participants in emotion processing, ToM and communication skills. There were no significant correlations between the variables of social cognition and communication skills in the group of AS. Taken together, results suggest that people with a diagnosis of AS present a deficit in ToM and emotional processing as well as in communication skills. However, it was not possible to identify a significant association between the variables of social cognition and communication skills.
\end{abstract}

Keywords: Asperger syndrome, social cognition, communication skills.

\section{Cognición social y habilidades de comunicación en adultos jóvenes con sindrome de Asperger}

RESUMEN. El objetivo de este trabajo es estudiar la ejecución de personas con síndrome de Asperger (AS) en tareas de cognición social y de habilidades comunicacionales. Para ello se evaluaron veinte adultos jóvenes en tres áreas de la cognición social, reconocimiento de emociones básicas, reconocimiento de emociones complejas y Teoría de la Mente (ToM). Además los participantes completaron un autoinforme sobre habilidades de comunicación social. Los resultados indican que los adultos con SA obtienen una peor ejecución en las tareas de procesamiento de las emociones (tanto básicas como complejas), en tareas de ToM y en habilidades de comunicación. No se han obtenido correlaciones significativas entre las variables de cognición social y las habilidades de comunicación. En conjunto, los resultados sugieren que las personas con un diagnóstico de SA presentan un déficit en el procesamiento emocional y de ToM, así como en las habilidades de comunicación. Sin embargo, no fue posible identificar una asociación significativa entre las diferentes variables de cognición social evaluadas y las habilidades de comunicación.

Palabras clave: Síndrome de Asperger, cognición social, habilidades de comunicación. 


\section{INTRODUCTION}

Emotional processing is related to the perception and use of emotions. Emotion perception refers to the ability of infering emotional information from facial expressions, vocal inflections, or the combination of both (Horan, Kern, Green, \& Penn, 2008). Most studies that have been carried out on emotional processing in Asperger Syndrome (AS) have focused on basic emotion identification and the results have been contradictory, with some authors saying that children with AS have difficulty in recognizing basic emotions through facial expressions, voice tone or both (Kuusikko et al., 2009; Yirmiya, Sigman, Kasari, \& Mundy, 1992), while others maintain that there are no difficulties in this area (Boucher, Lewis, \& Collis, 2000; Grossman, Klin, Carter, \& Volkmar, 2000). Yang, Savostyanov, Tsai, \& Liou (2011) found that adolescents and young adults were able to recognize basic emotions in others, but such recognition was connected with additional mental effort when compared to neurotypical controls. On the other hand, studies that have evaluated the identification of more complex emotions have demonstrated greater and more consistent evidence of the difficulty to recognize these types of emotions whether in children (Baron-Cohen, O'Riordan, Stone, Jones \& Plaisted, 1999; Capps, Yirmiya, \& Sigman, 1992; Happé, 1994; Yirmiya et al., 1992) or in adults (Golan, Baron-Cohen, \& Hill, 2006; Happé, 1994; Shamay-Tsoory, 2008).

The emotions and feelings of others are interpreted either through voice tone, or through facial and corporal expressions (Kuusikko et al., 2009). If we focus only on facial expressions we enter the domain of face processing. People with AS have difficulties in reading facial expressions because they process faces as they do objects and they seem to pay attention only to the individual components of a face. Face processing can be described as the central source of information about the emotion but the ability to recognize the emotional state of others requires the ability to pay attention and focus on relevant information (Kuusikko et al., 2009). Several studies have reported that people with AS show reduced attention to eyes, which is the region of the face providing more information about the expression of different emotions, and this is true for both children and adolescents (Freeth, Chapman, Ropar, \& Mitchell, 2010; Falkmer, Bjällmark, Larsson, \& Falkmer, 2011; Klin, Jones, Schultz, Volkmar, \& Cohen, 2002; Vulchanova, Talcott, Vulchanova, \& Stankova, 2012) as well as for adults (Baron Cohen, Wheelwright, \& Jolliffe, 1997b). Even when they are capable of establishing eye contact, the interpretation that they make about the information provided from the other person's eyes is not very efficient (Attwood, 2009). It has been suggested that a deficit in processing emotions can be a result of inadequate face processing (Figueira, Fuentes, \& Ruiz, 2011).

Theory of Mind (ToM) refers to the ability to understand that others have mental states that differ from one's own and the capacity to make correct inferences about the content of those mental states. Processes typically associated with ToM involve the ability to understand false beliefs, hints, intentions, met- 
aphor, and irony (Horan et al., 2008). Several studies have demonstrated that people with AS present difficulties in ToM (Lugnegård, Hallerbäck, Hjärthag, \& Gillberga, 2013) and this is true for both children and adolescents (Frith, 2006; Happé, 1994; Kaland, Callesen, \& Moller-Nielsen, 2008) and for adults as well (Happé, 1994; Spek, Scholte, \& Berckelaer-Onnes, 2010). People with AS cannot reflect automatically about the mental states of others and present difficulties in "putting themselves into others' shoes" or taking perspectives (Frith, 2006). For that reason, Baron-Cohen (1995) states that they are mindblind. One of the consequences of presenting a deficit in ToM is the tendency to make literal interpretations of everything that is said by others. Metaphors, sarcasm and irony also generate much confusion (Kaland, Mortensen, \& Smith, 2011; Llaneza, DeLuke, Batista, Crawley, Christodulu, \& Frye, 2010; Norbury, 2005).

When presented with "advanced" and contextually complicated ToM tasks, requiring mind-reading abilities, individuals with AS demonstrated significantly more difficulties in solving these tasks compared with matched controls (BaronCohen et al., 1997a; Baron-Cohen et al., 1997b; Happé, 1994; Kalland et al., 2008; Spek et al., 2010; Zalla, Sav, Stropin, Ahade, \& Leboyer, 2009).

Despite being considered as having good general vocabulary and being advanced in their lexical knowledge (Stothers \& Cardy, 2012), individuals with AS present major difficulties on a communicational level. One of the most visible is the incapability of modifying language in accordance with social circumstances. Pragmatics is the area that studies the use of language in social contexts and it is extremely affected in AS (Paul, Orlovski, Marcinko, \& Volkmar, 2009). Peculiarities of tone, inflexion and rhythm of the voice are evident in the person with AS (Paul, Augustyn, Klin, \& Volkmar, 2005; Vulchanova et al., 2012). People with AS also have difficulties in understanding the importance of voice tone, inflexions or the accentuation of certain words when they are listening to others (Llaneza et al., 2010). These subtle keys are very important if we want to identify the intentions, thoughts and emotions of others. There are also reports of difficulties in figurative language processing in individuals with AS, both for comprehension and generation (Gold, Faust, \& Goldstein, 2010; Vulchanova et al., 2012). Normally, people with AS do not like to be interrupted when they are talking, yet they usually interrupt others or continue talking when they should not do so (Grandin, 1995). This normally happens because they are not able to interpret the signs that indicate that they should not interrupt or continue talking (Llaneza et al., 2010). The signs that demonstrate agreement and the feeling of being listened to with attention and empathy are not present in the communication process of a person with AS (Attwood, 2009; Ozonoff \& Miller, 1995). This occurs because these abilities require being able to take account of the other person's perspective and to see things from their point of view.

This study focuses on how young adults with Asperger syndrome carry out emotion recognition and ToM tasks and on their communication skills. It will also look for any positive correlations between social cognition domains (emo- 
tion recognition and ToM) and between variables of social cognition and communication.

\section{METHOD}

\section{Participants}

Twenty young adults (between 16 and 25 years old) participated in the study. Ten of them had a diagnosis of AS and the other ten participants were healthy controls. The AS participants were recruited from a centre specialized in developmental disorders (CADIn). All participants gave written informed consent to participate in the study. This was conducted in accordance with the guidelines of the Helsinki Declaration.

Inclusion criteria in the AS group were: diagnosis of AS according to the DSM-IV-TR; cognitive skills within the normal range as measured by the WAISIII or WISC-III; age equal or superior to sixteen years old. Participants in the control group were recruited from the community, had typical development (i.e. absence of a diagnosis of AS) and demographic characteristics similar to those in the AS group.

\section{Procedure and assessment}

The reduced version of the WAIS-III proposed by Blyler, Gold, Iannone, \& Buchanan (2000) was used to estimate IQ in the control group. There were two AS participants and two healthy control participants that were assessed with the WISC III, because they were 16 years old at the time of the assessment.

We administered two tests to evaluate the recognition of basic emotions and the recognition of complex emotions. The first was the Face Emotion Identification Test (FEIT) from Kerr \& Neale (1993). This test, in its original form, consists of 19 photographs of faces of people, expressing the six basic emotions (happiness, anger, fear, sadness, surprise and shame). However, in the present study, we used an abbreviated version, since we considered that some of the photos raised some ambiguity in the answers, which can probably be explained by socio-cultural differences. Thus, a group of 33 healthy participants completed the FEIT and their results were used to select those photographs that obtained a $90 \%$ of agreement on the correct answer. Only 10 of them obtained $90 \%$ of concordance in the response (photographs number: 1, 3, 4, 5, 8, 10, 11, 12, 13, 15).

The recognition of complex emotions was assessed using the Cambridge Mindreading (CAM) Face Voice Battery (Golan et al., 2006). An abbreviated form of it was created to be used in the present study. At first, we excluded the voice task, since the recordings were in a different language than that spoken by the participants in this study. We chose to use only the videos and to translate the adjectives and their definition into Portuguese. We decided to apply this test to the sample of 33 participants that were also measured in the FEIT. The criterion 
to keep a video in the test was the same as that used in FEIT, agreement of $90 \%$ of the participants in the correct answer. Only 29 of the videos (video numbers: $1,3,4,5,8,9,10,11,12,13,14,16,20,26,27,29,34,36,37,38,41,42,43,45$, $46,47,48,49$ and 50) obtained $90 \%$ of concordance in the response.

ToM was measured with the Faux Pas Recognition Test. It was created by Baron-Cohen et al. (1999) to assess the ability for mentalizing in children with high functioning autism (between 7 and 11 years) who were able to perform successfully first and second order ToM tasks. The test is frequently quoted and several studies have shown that it is useful when the aim is to evaluate the ability to infer mental states not only in children (Baron-Cohen et al., 1999) but also in adults (Spek et al., 2010; Zalla et al., 2009). In this test, participants were asked whether anyone in the story said something awkward and questioned the underlying motive. The test comprises of twenty stories, ten with and ten without a faux pas. To score and interpret the answers, the instructions of Baron-Cohen et al. (1999) were used.

Social communication skills were assessed with the Questionnaire of Social Communication Skills (SCSQ) (McGann, Werven, \& Douglas, 1997), which has already been used to assess communication skills in Asperger syndrome (TurnerBrown, Perry, Dichter, Bodfish, \& Penn, 2008) because it evaluates some communication skills that are considered relevant in AS.

\section{RESULTS}

Statistical analyses were conducted using the Statistical Package for Social Sciences (SPSS v.15). The demographic characteristics of the participants are presented in Table 1. The AS and control group only differed in the codes subtest of the WAIS-III used to estimate IQ. This difference could be explained by the symptoms present in AS, particularly motor clumsiness, related with difficulties in fine motor skills, like poor handwriting and lax joints as referred by Attwood (2009), which greatly could impair performance on this subtest.

Table 1. Sample characteristics. Means and Standard Deviations of SocioDemographic Variables and IQ

\begin{tabular}{|c|c|c|c|c|}
\hline & $\begin{array}{l}\text { AS Group } \\
(\mathrm{n}=10) \\
(\text { Mean and SD) }\end{array}$ & $\begin{array}{l}\text { Control Group } \\
(\mathrm{n}=10) \\
(\text { Mean and SD) }\end{array}$ & $\begin{array}{l}t \text { - Test / } \\
\chi^{2} \text {-Test }\end{array}$ & $p$ \\
\hline Age & $20.90(2.73)$ & $20.70(2.83)$ & $t=-0.161$ & .874 \\
\hline Years of study & $12.6(2.01)$ & $12.6(1.65)$ & $t=0$ & 1 \\
\hline Sex, male:female & $8: 2$ & $8: 2$ & $\chi^{2}=0.001$ & 1.000 \\
\hline Estimated IQ & $97.10(21.12)$ & $105.60(12.09)$ & $t=1.104$ & .284 \\
\hline Information subtest & $11.90(2.85)$ & $10.40(1.65)$ & $t=-1.443$ & .170 \\
\hline Arithmetic subtest & $10.10(4.33)$ & $11.60(2.32)$ & $t=0.965$ & .351 \\
\hline Codes subtest & $5.90(3.57)$ & $10.90(3.57)$ & $t=3.129$ & .006 \\
\hline Cubes subtest & $10.20(4.02)$ & $10.50(2.59)$ & $t=0.198$ & .845 \\
\hline
\end{tabular}


Table 2 shows the scores in the measures of social cognition and social functioning for both groups. Results showed significant differences between the two groups in all measures except in the control questions of the faux pas test. Considering that these questions are related with the understanding of each story, this result indicates that both groups had a good understanding of all stories of the test, suggesting that a poor performance on the other questions is due to difficulties in theory of mind and not to a misinterpretation of the stories. Effect sizes were calculated to determine the magnitude of the difference between the two groups using Cohen's $d$ formula (Cohen, 1988).

Effect sizes in the emotion recognition dimension were large, 1.40 in the case of basic emotions (FEIT) and 1.61 in complex emotions (CAM). AS participants have more difficulties in the recognition of basic and complex emotions than control participants and this reveals the presence of an impairment in emotion recognition in AS young adults.

In the case of stories with faux pas, the effect size was large (1.05), suggesting that young adults with AS are less able to respond to questions involving advanced ToM tasks. In the control stories the effect size was 1.74. Unlike what happened with the faux pas stories, where the goal is to identify a faux pas, and young adults with AS had difficulties in detecting it, on the control stories, where there was not a faux pas, young adults with AS considered that there was something that should not have been said or done when in fact there was not. Finally, the effect size in communication skills was also large (0.98), pointing to a deficit in communication skills in AS young adults.

Table 2. Means and Standard Deviations on Measures of Social Cognition and Social Functioning and Differences between Patients and Healthy Groups (Student T Test) and its Effect Size.

\begin{tabular}{llllll}
\hline & $\begin{array}{l}\text { AS Group } \\
\text { (Mean and SD) }\end{array}$ & $\begin{array}{l}\text { Control Group } \\
\text { (Mean and SD) }\end{array}$ & $t$-Test & $p$ & $\begin{array}{l}\text { Effect } \\
\text { Size }\end{array}$ \\
\hline Faux Pas Stories & $38.30(11.50)$ & $48.60(8.07)$ & 2.318 & .032 & 1,05 \\
Control Stories (FP) & $17.40(2.99)$ & $20.00(0.00)$ & 2.751 & .022 & 1,74 \\
Control Questions (FP) $_{\text {FEIT }^{\mathrm{a}}}^{40.00(0.00)}$ & $40.00(0.00)$ & & & \\
CAM $^{\mathrm{b}}$ & $8.30(1.34)$ & $9.60(0.52)$ & 2.867 & .015 & 1,40 \\
SCSQ $^{\mathrm{c}}$ & $22.00(5.52)$ & $27.70(1.57)$ & 3.143 & .006 & 1,61 \\
\hline
\end{tabular}

${ }^{\mathrm{a}}$ Facial Emotion Identification Test.

${ }^{\mathrm{b}}$ Cambridge Mindreading Face Voice Battery.

${ }^{\mathrm{c}}$ Social Communication Skills Questionnaire.

Correlations between social cognition measures, and between social cognition and communication skills measures were not significant in AS participants (Table 3). Contrary to what was expected, social cognition variables had no clear relation to each other or to the communication skills variable. Only the relations between CAM and SCSQ, $R=.58, p=.082$, and between the two measures of emotion recognition FEIT and CAM, $R=.57, p=.084$, could be considered 
marginally significant. That is, the better the young adults with AS were in recognizing complex emotions, the better their communication skills. And, at the same time, better recognition of basic emotions may be associated with better recognition of complex emotions. Probably, with a larger sample these two correlations could have reached significance.

\section{Table 3. Correlations between Social Cognition Measures and Communication Skills in as Patients}

\begin{tabular}{llllll}
\hline & FP Stories & Control Stories & FEIT & CAM & SCSQ \\
\hline FP Stories $^{\mathrm{a}}$ & 1 & & & & \\
Control Stories & .11 & 1 & & & \\
FEIT $^{\mathrm{b}}$ & .20 & .16 & 1 & & \\
CAM $^{\mathrm{c}}$ & -.24 & -.34 & .57 & 1 & \\
SCSQ $^{\mathrm{d}}$ & 0.20 & -.05 & .35 & .58 & 1 \\
\hline
\end{tabular}

\footnotetext{
${ }^{\mathrm{a}}$ Faux Pas Stories

${ }^{\mathrm{b}}$ Facial Emotion Identification Test.

${ }^{\mathrm{c}}$ Cambridge Mindreading Face Voice Battery.

${ }^{\mathrm{d}}$ Social Communication Skills Questionnaire.
}

\section{DISCUSSION}

Consistent with previous studies (Baron-Cohen et al., 1997a; Baron-Cohen et al., 1997b; Baron-Cohen et al., 1999; Happé, 1994; Kalland et al., 2008; Spek et al., 2010; Capps et al., 1992; Golan et al., 2006; Shamay-Tsoory, 2008; Yirmiya et al., 1992), we found that young adults with a diagnosis of AS present lower levels of performance in emotion recognition, ToM and communication skills measures than neurotypical young adults. AS young adults showed a deficit in two components of social cognition: recognition of basic and complex emotions and ToM as well as in a component of everyday functioning: communication skills. However, it is important to emphasize that in this study emotional processing was measured in a more accurate way, since the instruments used to assess the identification of basic and complex emotions contained only items with a high probability of correct recognition as measured in a sample of normative participants.

According to the literature, being able to read, interpret and react on the facial emotional information from others are essential abilities in social interaction and social development (Baron-Cohen et al., 1997b; Tager-Flusberg, 2003). It has also been reported that findings of difficulties on a basic level of emotion recognition in adults with AS indicates difficulties in social functioning in daily life (García-Villamisar, Rojahn, Zaja, \& Jodra, 2010). The abovementioned studies clearly establish an association between social cognition skills and communication and social skills. However, although it was hypothesized that social cognition deficits might explain some everyday impairments in AS individuals on a communicational level, we did not find significant relations between social cognition and social communication measures in our study probably because of 
the size of our sample. In addition, as Frith \& Happé (1999) stated, the use of measures of self-registration in AS is controversial because of the introspective skills deficits associated with this disorder. That is, AS individuals seem to have difficulty in reflecting on their internal states and this may influence their selfevaluation through a questionnaire. In addition, as reported by Cederlund, Hagberg, \& Gillberg (2010), adolescents and young adults with AS underrate their level of handicap regarding some key features of the core social deficit, when compared to how parents regard their functioning. This might have occured in our study, which could have contributed to the non existence of an association of social cognition measures and social communication measure.

Our results have implications for the design and/or improvement of social functioning training programs for young adults with AS. The trainnig of social cognitive skills in people with good cognitive potential, such as people with a diagnosis of AS, will promote improvements in their social functioning.

\section{REFERENCES}

Attwood, T. (2009). Guía del síndrome de Asperger. Barcelona: Ediciones Paidós Ibérica, S.A.

Baron-Cohen, S. (1995). Mind blindness: An essay on autism and theory of mind. Cambridge: MIT Press.

Baron-Cohen, S., Jolliffe, T., Mortimore, C., \& Robertson, M. (1997a). Another advanced test of theory of mind: Evidence from very high functioning adults with autism or Asperger syndrome. Journal of Child Psychology and Psychiatry, 38, 813-822.

Baron-Cohen, S., Wheelwright, S., \& Jolliffe, T. (1997b). Is there a "language of the eyes"? Evidence from normal adults and adults with autism or Asperger syndrome. Visual Cognition, 4, 311-331.

Baron-Cohen, S., O’Riordan, M., Stone, V., Jones, R., and Plaisted, K. (1999). Recognition of Faux Pas by Normally Developing Children and Children with Asperger Syndrome or High-Functioning Autism. Journal of Autism and Developmental Disorders, 29, 407-418.

Blyler, C. R., Gold, J. M., Iannone, V. N., and Buchanan, R. W. (2000). Short form of the WAIS-III for use with patients with schizophrenia. Schizophrenia Research, 46, 209-215.

Boucher, J., Lewis, V., and Collis, G. M. (2000). Voice processing abilities in children with autism, children with specific language impairments and young typically developing children. Journal of Child Psychology and Psychiatry and Allied Disciplines, 41, 847-857.

Capps, L., Yirmiya, N., and Sigman, M. (1992). Understanding of simple and complex emotions in non-retarded children with autism. Journal of Child Psychology and Psychiatry, 33, 1169-1182.

Cederlund, M., Hagberg, B., and Gillberg, C. (2010). Asperger syndrome in adolescent and young adult males. Interview, self - and parent assessment of 
social, emotional, and cognitive problems. Research in Developmental Disabilities, 31, 287-298.

Cohen, J. (1988). Statistical power analysis for the behavioural sciences $\left(2^{\text {nd }}\right.$ ed.). Hillsdale (NJ): Lawrence Erlbaum Associates.

Falkmer, M., Bjällmark, A., Larsson, M., and Falkmer, T. (2011). Recognition of facially expressed emotions and visual search strategies in adults with Asperger syndrome. Research in Autism Spectrum Disorders, 5, 210-217.

Figueira, M., Fuentes, I., \& Ruiz, J. C. (2011). Lost in the Social World: How Social Cognitive Deficits Affect Social Functioning of People with Asperger Syndrome. In. L. L'Abate (ed.), Mental illnesses - understanding, prediction and control (pp. 385-406). Rijeka: InTech.

Freeth, M., Chapman, P., Ropar, D., and Mitchell, P. (2010). Do gaze cues in complex scenes capture and direct the attention of high-functioning adolescents with ASD? Evidence from eye-tracking. Journal of Autism and Developmental Disorders, 40, 534-547.

Frith, U. (2006). Autismo: Hacia una explicación del enigma (2a ed.). Madrid: Alianza Editorial.

Frith, U., \& Happé, F. (1999). Theory of mind and self-consciousness: What is it like to be autistic? Mind and Language, 14, 1-22.

García-Villamisar, D., Rojahn, J., Zaja, R. H., and Jodra, M. (2010). Facial emotion processing and social adaptation in adults with and without autism spectrum disorder. Research in Autism Spectrum Disorders, 4, 755-762.

Golan, O., Baron-Cohen, S., \& Hill, J. (2006). The Cambridge Mindreading (CAM) face-voice battery: Testing complex emotion recognition in adults with and without Asperger syndrome. Journal of Autism and Developmental Disorder, 36, 169-183.

Gold, R., Faust, M., and Goldstein, A. (2010). Semantic integration during metaphor comprehension in Asperger syndrome. Brain and Language, 113, 124-134. http://dx.doi.org/10.1016/j.bandl.2010.03.002

Grandin, T. (1995). Thinking in pictures and other reports from my life with autism. New York: Doubleday.

Grossman, J. B., Klin, A., Carter, A. S., and Volkmar, F. R. (2000). Verbal bias in recognition of facial emotion in children with Asperger syndrome. Journal of Child Psychology and Psychiatry and Allied Disciplines, 41, 369-379.

Happé, F. (1994). An advanced test of theory of mind: Understanding of story character's thoughts and feelings by able autistic, mentally handicapped, and normal children and adults. Journal of Autism and Developmental Disorders, 24, 129-154.

Horan, W. P., Kern, R. S., Green, M. F., and Penn, D. (2008). Social Cognition Training for Individuals with Schizophrenia: Emerging Evidence. American Journal of Psychiatric Rehabilitation, 11, 205-252.

Kaland, N., Callesen, K., Moller-Nielsen, A., Mortensen, E. L., and Smith, L. (2008). Performance of children and adolescents with Asperger syndrome or high-functoning autism on advanced theory of mind tasks. Journal of Autism 
and Developmental Disorders, 38, 1112-1123.

Kaland, N., Mortensen, E. L., and Smith, L. (2011). Social communication impairments in children and adolescents with Asperger syndrome: Slow response time and the impact of prompting. Research in Autism Spectrum Disorders, 5, 1129-1137.

Kerr, S., and Neale, J. (1993). Emotion perception in schizophrenia: Specific deficit or further evidence of generalized poor performance? Journal of Abnormal Psychology, 102, 312-318.

Klin, A., Jones, W., Schultz, R., Volkmar, F., and Cohen, D. (2002). Visual fixation patterns during viewing of naturalistic social situations as predictors of social competence in individuals with autism. Archives of General Psychiatry, 59, 808-816.

Kuusikko, S., Haapsamo, H., Jansson-Verkasalo, E., Hurtig, T., Matilla, M., Ebeling, H., Jussila, K., Bölte, S., and Moilanen, I. (2009). Emotion recognition in children and adolescents with autism spectrum disorders. Journal of Autism and Developmental Disorders, 39, 938-945.

Llaneza, D. C., DeLuke, S. V., Batista, M., Crawley, J. N., Christodulu, K. V., and Frye, C. A. (2010). Communication, interventions, and scientific advances in autism: A commentary. Physiology and Behavior, 100, 268-276.

Lugnegård, T., Hallerbäck, M. U., Hjärthag, F., and Gillberga, C. (2013). Social cognition impairments in Asperger syndrome and schizophrenia. Schizophrenia Research, 143, 277-284.

McGann, W., Werven, G., and Douglas, M. (1997). Social competence and head injury: A practical approach. Brain Injury, 11, 621-628.

Norbury, C. F. (2005). The relationship between theory of mind and metaphor: Evidence from children with language impairment and autistic disorder. British Journal of Developmental Psychology, 23, 383-399.

Ozonoff, S., and Miller, J. N. (1995). Teaching theory of mind: A new approach to social skills training for individuals with autism. Journal of Autism and Developmental Disorders, 25, 415-433.

Paul, R., Augustyn, A., Klin, A., and Volkmar, F. (2005). Perception and production of prosody by speakers with autism spectrum disorders. Journal of Autism and Developmental Disorders, 35, 205-220.

Paul, R., Orlovski, S. M., Marcinko, H. C., and Volkmar, F. (2009). Conversational behaviors in youth with high-functioning ASD and Asperger syndrome. Journal of Autism and Developmental Disorders, 39, 115-125.

Rutherford, M. D., and Towns, A. M. (2008). Scan path differences and similarities during emotion perception in those with and without autism spectrum disorders. Journal of Autism and Developmental Disorders, 38, 1371-1381.

Shamay-Tsoory, S. G. (2008). Recognition of 'fortune of others' emotions in Asperger syndrome and high functioning autism. Journal of Autism and Developmental Disorders, 38, 1451-1461.

Spek, A. A., Scholte, E. M., and Berckelaer-Onnes, I. A. (2010). Theory of mind in adults with HFA and Asperger syndrome. Journal of Autism and Develop- 
mental Disorder, 40, 280-289. http://dx.doi.org/10.1007/s10803-009-0860-y Spezio, M. L., Adolphs, R., Hurley, R. S. E., and Piven, J. (2007). Abnormal use of facial information in high-functioning autism. Journal of Autism and Developmental Disorder, 37, 929-939.

Stothers, M. E., Cardy, J. O. (2012). Oral language impairments in developmental disorders characterized by language strengths: A comparison of Asperger syndrome and nonverbal learning disabilities. Research in Autism Spectrum Disorders, 6, 519-534.

Tager-Flusberg, H. (2003). Exploring the relationship between theory of mind and social-communicative functioning. In B. Repacoli and V. Slaughter (Eds.), Individual differences in theory of mind. Implications for typical development (pp.197-212). New York: Psychology Press.

Turner-Brown, L., Perry, T. D., Dichter, G. S., Bodfish, J. W., and Penn, D. L. (2008). Brief report: Feasibility of social cognition and interaction training for adults with high functioning autism. Journal of Autism and Developmental Disorders, 38, 1777-1784.

Vulchanova, M., Talcott, J. B., Vulchanova, V., and Stankova, M. (2012). Communication: Language against the odds, or rather not: The weak central coherence hypothesis and language. Journal of Neurolinguistics, 25, 13-30.

Yang, H. H., Savostyanov, A. N., Tsai, A. C., and Liou, M. (2011). Face recognition in Asperger syndrome: A study on EEG spectral power changes. Neuroscience Letters, 492, 84-88.

Yirmiya, N., Sigman, M. D., Kasari, C., and Mundy, P. (1992). Empathy and cognition in high-functioning children with autism. Child Development, 63, $150-160$.

Zalla, T., Sav, A., Stopin, A., Ahade, S., and Leboyer, M. (2009). Faux Pas Detection and Intentional Action in Asperger Syndrome. A Replication on a French Sample. Journal of Autism and Developmental Disorders, 39, 373-382. 